\title{
Specific aspects of the state regulation of the national market inclusive tourism
}

\author{
Larysa Obolentseva ${ }^{1}$, Iryna Andrenko ${ }^{1}$, Olena Uhodnikova $^{1,}{ }^{*}$, Mariia Pokolodna $^{1}$, Anton \\ Ryabev $^{1}$, and Kostiantyn Viatkin ${ }^{1}$ \\ ${ }^{1}$ O.M. Beketov National University of Urban Economy in Kharkiv, 61002, 17 Marshal Bazhanov st., \\ Kharkiv, Ukraine
}

\begin{abstract}
The article is devoted to the actual topic of inclusive tourism development in Ukraine. According to various sources, the number of tourists with special needs in developed countries is an average of $20 \%$. Trends in the tourism industry development indicate an increase in this type of tourism, therefore, inclusive tourism has significant financial and economic potential. World tourism trends indicate that inclusive tourism shows the highest growth rates. The concept of "tourism for all" has a global character and are declared in the provisions of the international documents of the United Nations. A significant contribution to the development and promotion of inclusive tourism is made by the World Tourism Organization. The article analyzes the experience of Ukraine in the implementation of inclusion projects. The main regulatory documents, governing norms and standards to ensure barrier-free access are defined. Based on the analysis, the proposals for improving the effectiveness of state regulation of the inclusive tourism development in Ukraine based on the best international practices, considering problematic aspects and prospects for the introduction of inclusion in Ukraine, have been developed.
\end{abstract}

\section{Articulation of issue}

The tourism industry is actively developing. The number of outbound tourists exceeds one billion people every year. In 2018, the tourism industry reached a record increase in tourist flows, which is $12 \%$ of the previous year. Today, most countries consider the prospects for the development of tourism not only as a separate sector of the national economy but as a strategic vector for the development of the national economy. One of the actual concepts of tourism development at the state level is to ensure the inclusiveness of the tourism space the availability of tourist services for all. Among the features of the tourism industry, which, in particular, is typical for the service sector in general, there is a need for tourists to ensure safety and comfort in receiving tourist services, while maintaining the economic balance and availability of such services for different segments of the population is important. Therefore, the problem of finding ways to implement the concept of "tourism is accessible to all" is relevant and requires further consideration.

* Corresponding author: ugodnikova16@gmail.com 
Basic tenets of inclusive tourism development at the state level are incorporated in the basic provisions of the United Nations Development Program, in particular, "tourism accessibility for all" are defined in the Bali Declaration $[1,2]$, where inclusion is defined as one of the priorities of the strategic development of mankind, considering the need to provide mass tourism, including its accessibility for inclusive categories of the population. One of the organizations, which actively promotes the barrier-free concept is the World Health Organization, which defines the priorities of infrastructure development to ensure comfort for people with disabilities [3]. The study results of the UN Department of Social and Economic Affairs, where the number of potential tourists of social categories in the trend until 2050 was determined, are interesting from the point of view of determining the prospects for the development of inclusive tourism in the countries [4]. The trend indicates a steady increase in the number of social categories of tourists. The basic tenets of the rights of people with disabilities are combined in the framework of globalization processes into a single concept, which, among other things, determines the need to ensure the availability of tourism for all categories of the population [1].

\section{Analysis of the latest researches and publications}

The works of many scientists are devoted to the issues of ensuring the inclusiveness of the infrastructure and barrier-free environment. In particular, Laurie Dyer and Simon Darcy conducted a study on the profitability of inclusive tourism projects. The accessible tourism concepts were identified as financially attractive because they determine the everincreasing volumes of the state and the private sector profitability due to the popularization of this type of tourism. The authors have defined the main postulates of financial and economic support for inclusive tourism and problems hindering its further development [5]. Dimitrios Buhalis, Simon Darcy and Ivor Ambrose have identified promising areas for inclusive tourism development and the world's best practices for creating a barrier-free environment [6]. The most inclusive-oriented are the areas of tourism in the United States and Western European countries. Other regions are less equipped for this type of tourism. Shakespeaare T. has explored the problematic aspects and prospects for the inclusive tourism development and has identified the main aspects of the inclusiveness development for developing and underdeveloped countries [7]. Walker N.K.G. and Chen Y. have analyzed the rights of people with disabilities and problematic aspects within which these rights may be limited, e.g., with insufficient legislative support, insufficient technical or technological component of the inclusiveness development in a particular country, region or even at a separate local level [8]. Despite the significant attention of the authors to the problems of the inclusive tourist space development, the rapid development of tourism and innovative technologies determine the relevance of continuing research on improving inclusive tourism effectiveness.

\section{Purposes and objectives}

The paper aims to identify the ways of inclusive tourism development in Ukraine, taking into account the world experience in the implementation of inclusion projects. According to the aim, there are a number of the following tasks:

- to analyze trends of the inclusive tourism industry development;

- to identify categories of people who may require the creation of an inclusive space;

- to analyze the international experience of inclusive tourism development;

- to identify the specific aspects of the normative and legal support for the national inclusive tourism development; 
- to develop proposals on improving the effectiveness of ensuring inclusiveness in the field of tourism in Ukraine at the state level.

\section{Statement of basic materials}

Tourist trip involves many aspects related to possible inaccessibility for certain tourists. Tourist "inaccessibility" can be associated with the technical characteristics of accommodation, with the implementation of the transportation of tourists, objects of the restaurant industry, information limitations and many other factors. The World Tourism Organization (WTO) deals with the issues of ensuring the availability of tourist services, and which has an appropriate profile and ensures the development of barrier-free at the global level. For the first time, the issue of the availability of tourist services was considered at the General Assembly of the WTO in 1991 [3]. The growing demand for tourism services has led to the differentiation of persons who use them by age, gender, social and other levels. Due to the increase in the number of travellers, the requirements for ensuring the availability of tourist services began to grow in accordance with the needs of consumers. In 2007, the Convention on the Rights of Persons with Disabilities, the main postulate of which was the determination of equal rights for people, regardless of the presence or absence of a person's disability, became the initial impetus to the development of an inclusive tourist space and ensuring barrier-free access in all sectors of the service provision. The concept of "socially responsible tourism" emerged as a result of the implementation of the Convention on the Rights of Persons with Disabilities and defined the objectives of providing opportunities for comfortable travel for all tourists without exception $[1,2,4]$.

Among the main aspects of the provision of inclusive tourism services are the following priorities [1,3]:

- the inclusive infrastructure development;

- providing service processes with specially trained personnel who have not only sufficient qualifications but also relevant skills to work with people with limited mobility;

- ensuring transport accessibility for people with special needs;

- ensuring the availability of inclusive information;

- inclusive marketing development.

These key elements of ensuring the inclusiveness of the tourist services provision are important for the further tourism industry development because the trends in the tourist market indicate the urgency of finding ways to develop inclusiveness.

According to statistics [3], more than 1 billion of the world's population (approximately $15 \%)$ have a disability. There are population ageing trends, which have a significant dependence on the geographical factor of a particular regional location. If in 2000 the population of the Earth over 60 years has made more than 580 million people, now this figure has grown by more than $20 \%$. According to forecasts, in 2050 the percentage of the population over 60 years old on Earth will be $20 \%$, one-fifth of which will be over 80 years old. This trend is most visible in the countries of North America (USA, Canada) and Western Europe, and to a lesser extent in Asia. Population ageing is associated with the development of the health care system, which provides an increase in human longevity, and changes in the worldview of the urbanized world, in which young people increasingly prefer the birth of at most two children at a later age, giving priority to career building [9]. These indicators show that inclusive tourism in the near and strategic perspective will have sustainable growth indicators. Consequently, the provision of an inclusive tourist space is not simply defined as the ethical norm of modern society but also determines the prospects for increasing profitability from this type of business. Statistics on the number of tourists with disabilities who travel to different countries are presented in Fig. 1 


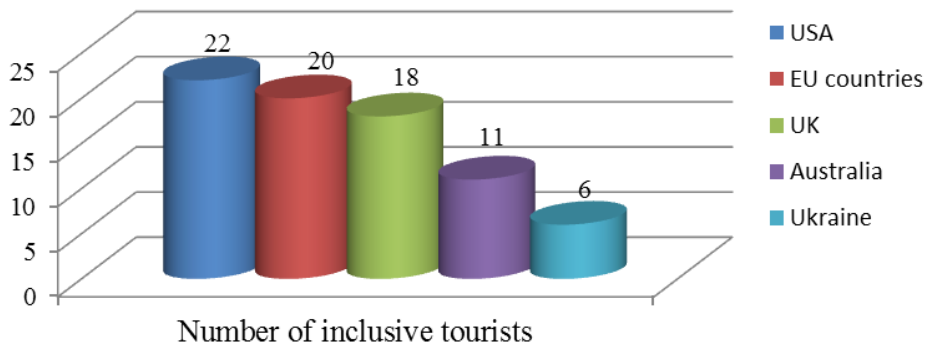

Fig. 1. Statistics of the inclusive tourists share in the total number of tourist flows [10].

The statistics indicate that the issue of inclusion is relevant and requires the reorientation of the world tourism industry to the "accessibility for all" format in order to realize the social function of tourism and opportunities for further growth in the volume of incomes in the industry [8-9].

It is advisable to identify categories of persons who may need an inclusive infrastructure. These categories include people with disabilities who may not be able to move freely, to hear information or visualize it. The category of inclusiveness includes social tourists, as well as persons of retirement age. Also, an inclusive infrastructure may be needed by pregnant women and children. In the case when a person visits another country and, for example, does not speak the local language, he may be in a situation of limited access to tourist services due to the inability to perceive written information, unlike the cases where infographics are used to explain and provide tourist information [10].

World experience in the development of inclusive tourism shows the following trends. One of the countries with the highest income from inclusive tourism and the number of tourists who belong to the limited categories of the population is the United States. The volume of income from inclusive tourism in this country is more than 17 billion dollars. Additionally, it is necessary to take into account the income from the provision of tourist services to persons who accompany an inclusive tourist. The most popular form of recreation among inclusive tourists in the United States is cruise tourism, which is defined as one of the safest in the world. This is due to the high technological and technical equipment of tourism facilities. More than 30 electronic resources in the United States dedicated to the provision of information, which can be useful for tourists with special needs [11].

The UK ranks second in terms of revenue from inclusive tourism. Total revenue is 12 billion dollars. The concept of inclusive tourism in this country is resolved to a comprehensive strategy for tourism development. Inclusion is recognized as one of the priorities for the development of tourism business at the state level. The number of online information resources on the inclusive infrastructure in the UK is more than 60 , which provides the maximum tourist information on the provision of inclusive services [5-6].

Australia ranks third in terms of revenue from inclusive tourism. Average revenue is $\$ 8$ billion a year. At the same time, the percentage of people with limited mobility in the structure of the country's population is quite high, which is $20 \%$. At the same time, more than $85 \%$ of the Australian population, which has inclusive needs, actively travel without barriers due to the provision of comfortable travel conditions and inclusive space [12].

According to statistics of the tourism development in the European Union countries, the volume of tourist flows of inclusive tourism is growing rapidly. The total number of people who require the creation of conditions for inclusion in the EU is more than 140 million, and revenues from inclusive tourism are more than 780 billion euros annually [6-7].

The specific features of inclusive tourism in the European Union include the following [13-15]: 
- expenses of tourists with special needs are greater than the average expenditures of tourists in this region;

- the development of inclusive tourism smooths the seasonality factor, because tourists with special needs prefer recreation not in the "peak season", thereby allowing travel companies to smooth out their own profitability during the year and minimize the risks of a tourist business;

- persons with special needs mainly travel within the country, that is, they increase the volume of domestic tourists, which allows keeping the revenues in own budget of the country in which favourable and comfortable conditions for the development of inclusive tourism are created.

One of the peculiarities of the inclusive tourism development in the EU countries is that the barrier-free space is mainly offered in accommodation facilities, represented mainly by large chain hotels, which follow international standards for ensuring the availability of services. Issues related to the development of inclusive infrastructure outside hotels, transport infrastructure and transport accessibility remain problematic. Information support for an inclusive space is provided by the website of the European Network for Accessible Tourism (ENAT), which combined all the necessary information for tourists with special needs, and which can be used when planning a trip or during it. Currently, only $10 \%$ of tourism companies offer inclusive tours to their clients, while the demand for them in EU countries, on average, is more than 20\% [16]. Tourist inclusive infrastructure is more developed in Western European countries, while in Eastern Europe, the problem is more complicated. Scandinavian countries pay special attention to both inclusive tourism infrastructure and providing opportunities for the development of social tourism in the country.

The development of inclusive tourism in Ukraine is in the initial stages. Although some elements of inclusion are beginning to be actively implemented, however, there are still no comprehensive approaches to systematization mechanisms for the provision of inclusive tourism. This situation is associated with a number of factors, among which are the following [16]:

- the limited financial capacity for creation of an inclusive infrastructure, limited government investment in the tourism industry and the lack of government programs to increase the investment attractiveness of the industry, which needs modernization, reconstruction and renewal of the existing tourism infrastructure to ensure its inclusiveness; - information vacuum caused by the lack of inclusive information, which must accompany the tourist, including information that should be provided by state, regional or local authorities, as well as the practical absence of national online and offline resources for inclusive tourism (except for information resources created by international organizations in Ukraine), lack of information on tourist offers of inclusive tourism by travel agents and tour operators;

- the need to develop and implement state projects of infrastructure renewal and modernization due to the advent of new technological solutions and innovative barrier-free facilities;

- the lack of a regulatory framework at the state level that clearly regulates the provision of limited mobility categories of tourists, as well as appropriate conditions for the availability of tourist services and related services;

- the lack of qualified personnel capable of providing competent assistance and services to persons with limited mobility and the absence of state programs to facilitate the training of such specialists.

These problems significantly impede the development of inclusive tourism in Ukraine. However, among the positive developments, it is advisable to note that the Ministry of Regional Development, Building and Housing and Communal Services of Ukraine has 
introduced new State Construction Standards, amended to the development of an inclusive infrastructure. A big advantage of these standards is their development in conjunction with representatives of public organizations of people with disabilities and the involvement of scientists who can justify the feasibility of introducing these building codes to ensure inclusiveness. Within the "Illusion" festival, which is held in Kharkiv (Ukraine), the conditions for the availability of museum premises for people with disabilities are created. The number of such tourist facilities of an inclusive nature is constantly growing.

To ensure the inclusive space of tourist infrastructure facilities, the authors have developed proposals for assessing the facility according to accessibility characteristics, based on the State Building Standards, and it is proposed to consider the following indicators:

- surface analysis of sidewalks (steps, slippery, roughness, etc.);

- the presence of ramps;

- installation of curb height in accordance with state building codes;

- lowering the curb at the exit points at pedestrian crossings, departures from parking lots, etc.;

- the arrangement of parking spaces for people with disabilities;

- equipping lifting devices for people with disabilities;

- the convenient location of buttons in elevators, door handles for accessibility for wheelchair users and small children;

- the availability of space for turning wheelchairs in vestibules, toilet rooms;

- the setting of automatic door closing system on the time required for the passage of persons with disabilities;

- the presence of shockproof glass;

- the availability of tactile information system;

- the presence of visual information system;

- the availability of interior items;

- the presence of light, tactile and graphic symbols;

- special conditions for the design and equipment of toilet and shower rooms;

- the availability of information that may be needed during consumption of tourist services (such as Info-graphic representation of information, its audible and tactile duplication).

Thus, after analyzing the main trends in the development of inclusive tourism, it can be determined that this development has social, financial and economic aspects. World practice shows that inclusive tourists increasingly travel and spend more money than the average tourist. So, inclusive tourism has significant prospects for further growth, and with state support for the development of tourism infrastructure, it can grow by more than $35 \%$ in the next five years. As a result of the study, the article proposes to define a list of indicators, which can serve as a basis for developing criteria for analyzing the provision degree of the inclusive infrastructure of tourist facilities at the state level.

\section{Conclusions}

Inclusive tourism is becoming increasingly popular in the world. In developed countries, the number of inclusive tourists on average is $20 \%$. The development of inclusive tourism has a steady upward trend. The categories of inclusive tourists include persons with disabilities, social categories of tourists, and those tourists who have become inclusive due to lack of information for familiarization or technical features of tourist infrastructure facilities. In Ukraine, the issue of inclusive tourism is under development, has no complex and systemic character. However, an essential step towards increasing the effectiveness of an inclusive infrastructure is the development of new state building codes, which are based on international practices of inclusion. In order to develop the proposals for improving the 
efficiency of ensuring inclusiveness in the field of tourism in Ukraine, the indicators, which can form the basis of criteria for evaluating tourist infrastructure facilities for ensuring barrier-free access for various categories of the population have been developed.

\section{References}

1. United Nations, Department of International Economic and Social Affairs. World Population Aging: 1950-2050 (2006). https://www.researchgate.net/scientificcontributions/50664949_United_Nations_Dept_of_International_Economic_and_Socia 1_Affairs

2. United Nations, Department of Economic and Social Affairs, Population Division, World Population Ageing (2015). https://www.un.org/en/development/desa/population/publications/pdf/ageing/WPA201 5_Report.pdf

3. World Health Organization, World Report on Disability (2011). http://www.who.int/disabilities/world_report/2011/report/en/

4. United Nations, Department of Economic and Social Affairs, Population Division, World Population Ageing $2017 \quad-\quad$ Highlights (2017). https://www.un.org/en/development/desa/population/publications/pdf/ageing/WPA201 7_Report.pdf

5. L. Dwyer, S. Darcy, ed. D. Buhalis, S. Darcy, The European Network for Accessible Tourism, 213-239 (2011). https://www.accessibletourism.org

6. D. Buhalis, S. Darcy, I. Ambrose, Channel View Publications (2012). https://www.un.org/disabilities/documents/convention/convoptprot-e.pdf

7. T. Shakespeare, Disability rights and wrongs revisited (Routledge, 2013).

8. N. K. G. Walker, Y. Chen, Journal of the Knowledge Economy, 10, 1700-1719, (2019). DOI: $10.1007 / \mathrm{s} 13132-018-0534-0$

9. A. Calveras, Tourism Managemen 74, 234-246, (2019). DOI: 10.1016/j.tourman.2019.03.002

10. A. Plyushteva, Journal of Policy Research in Tourism, Leisure and Events, 11(3), 407421, (2019). DOI: 10.1080/19407963.2018.1556673

11. Y. Chatkaewnapanon, J. M. Kelly, Journal of Place Management and Development, 12(3), 365-390, (2019). DOI: 10.1108/JPMD-09-2017-0094

12. M. Arbelo-Pérez, P. Pérez-Gómez, A. Arbelo, Current Issues in Tourism 22(8), 905 920, (2019). DOI: 10.1080/13683500.2017.1323850

13. G. Gupta, 5th International Conference on Information System Design and Intelligent Applications, INDIA 2018; Balaclava; Mauritius, 2018, $862411-419$ (2019). DOI: 10.1007/978-981-13-3329-3_38

14. A. Tuinstra, F. Van Den Abeele, A. Spooren, J. Vanrie, 15th Participatory Design Conference, PDC 2018; (Hasselt and Genk, Belgium, 2018). DOI: $10.1145 / 3210604.3210634$

15. C. Cockburn-Wootten, A. J. McIntosh, K. Smith, S. Jefferies, Journal of Sustainable Tourism, 26(9), 1483-1498 (2018). DOI: 10.1080/09669582.2018.1476519

16. R. Scheyvens, R. Biddulph, Inclusive tourism development Tourism Geographies, 20(4), 589-609 (2018). DOI: 10.1080/14616688.2017.1381985 